\title{
Oocyte Quality in Patients with Increased FSH Levels
}

\author{
Monise Santos ${ }^{1}$, Emerson Barchi Cordts $^{1}$, Bianca Bianco ${ }^{1}$, Caio Parente Barbosa ${ }^{1}$, Denise Maria \\ Christofolini ${ }^{1}$
}

${ }^{1}$ Instituto Ideia Fértil de Saúde Reprodutiva - Faculdade de Medicina do ABC

\begin{abstract}
Objective: The present study consists of quality comparison among oocytes retrieved from women under 37 years old showing increased levels of FSH (prone to premature ovarian insufficiency) and women at the same age with normal hormone levels.

Methods: Oocyte quality was accessed according to Lucinda L. Veeck parameters (1986) and the statistical analyses were carried out using Chisquared, SPSS for Windows 13.0 (SPSS, Inc., Chicago, IL). All pvalues were twotailed, and $95 \%$ confidence intervals (CIs) were calculated. A $P$ value $<0.05$ was considered statistically significant.

Results: Eight morphologic changes variables were considered in the study and two of them showed statistically significant differences between cases and controls: granular cytoplasm $(P=0.002)$ and presence of vacuoles $(P=0.025)$, both more frequent among the study group patients.

Conclusion: As a conclusion, patients with increased FSH levels presented oocytes with worst quality variables than controls. This can be an indicative of ovarian aging and can impact negatively on oocyte development into viable embryos.
\end{abstract}

Keywords: Premature Ovarian Insufficiency, Oocyte quality, FSH levels, Ovarian aging

\section{INTRODUCTION}

Oocyte quality is one of the factors that directly influences the development of a viable embryo in assisted reproduction procedures. The oocyte is a central regulator of multiple aspects of female fertility, including ovarian follicular development and early embryogenesis. A deficit in oocyte competence can lead not only to a failure of fertilization but also to a lower developmental rate after fertilization (Moussa et al., 2015).

According to Lucinda L. Veeck (1986) oocyte morphological aberrations can be classified according to the presence of granular cytoplasm, dark cytoplasm, vacuoles, debris, increased or absent perivitelline space, fragmented corpuscle, changes to oocyte shape, and zona pellucida alterations such as thick, thin, light and dark.

Ovarian aging is a major fact influencing oocyte quality. It is well known that the female reproductive capacity declines dramatically in the fourth decade of life as a result of an agerelated decrease in oocyte quality and quantity. The primary causes of reproductive aging and the molecular factors responsible for decreased oocyte quality remain elusive (BenMeir, 2015).

However, some women experience ovarian failure effects prematurely, before 40 years of age. The condition is not rare and affects one in every 100 women between 3039 years (Goswami \& Conway, 2005). Before complete failure and menopause establishment, FSH levels start to increase and the ovary becomes less responsive.

In 2013, the ESHRE Premature Ovarian Insufficiency (POI) Consensus (Braat, 2013) determined a new cut off level for $\mathrm{FSH}$ : $25 \mathrm{mUI} / \mathrm{ml}$; above which, patients can be classified with Premature Ovarian Insufficiency. The etiol- ogy of this condition is complex and the dysfunction may be secondary to autoimmune diseases, infections, iatrogenic exposure and genetic alterations such as cytogenetic abnormalities of the $X$ chromosome and gene mutations (Mattison et al., 1984; Alper et al., 1986; Conway, 1997; Anasti, 1998; Goswami \& Conway, 2005).

Due to the large incidence of POI, in Human Assisted Reproduction clinics it is possible to find a significant number of women whose FSH levels range between 10 and 25 $\mathrm{mUI} / \mathrm{ml}$. Nevertheless, no information about oocyte condition in these cases is described in the literature.

Thus, the goal of our study is to compare the incidence of oocyte alterations in women with prematurely increased $\mathrm{FSH}$ levels with their counterparts in the control group.

\section{MATERIALS AND METHODS \\ Cases}

The study group encompassed women aged from 30 to 39 years with changes in menstrual cycles, increased FSH levels in at least two dosages on the first three days of the cycle (between 12 and $25 \mathrm{mUI} / \mathrm{ml}$ ), and no other identified factor of ovarian damage such as surgery, chemo or radiotherapy, autoimmune diseases, endometriosis or PCOS.

Patients in the control group are women with normal FSH levels $(<10 \mathrm{mUI} / \mathrm{ml})$, with no ovulatory factor of infertility. All patients read and signed the informed consent form and were subjected to treatment involving assisted human reproduction.

\section{Oocyte quality assessment}

We analyzed 48 mature (MII) oocytes from the case group and 81 MII oocytes from the control group morphologically according to Lucinda L. Veeck parameters (1986). The variables analyzed were:

1) Granular cytoplasm

2) Dark cytoplasm

3) Presence of vacuoles

4) Presence of Debris

5) Increased perivitelline space

6) Fragmented polar corpuscle

7) Changes in oocyte shape

8) Changes on the zona pellucida thickness

We measured basal levels of follicle stimulating hormone (FSH) in patients with premature ovarian failure, using $5 \mathrm{~mL}$ of peripheral blood and commercial kit (Vidas $\AA$ FSH), using the Mini Vidas (bioMeriuex SA, 69280 Marcy l'Etoile, France) device.

\section{Statistical Analysis}

Statistical analyses were carried out using Chisquared SPSS for Windows 13.0 (SPSS, Inc., Chicago, IL). A $P$ value $<0.05$ was considered statistically significant.

\section{RESULTS}

The mean age of the study group patients was $37.1 \pm$ 15.0 years; and it was $36.6 \pm 4.5$ years old in the control group. 
Table 1. Study group $x$ Control group. Analyses of morphological variables

\begin{tabular}{|c|c|c|c|}
\hline $\begin{array}{l}\text { Morphological } \\
\text { Variables }\end{array}$ & $\begin{array}{c}\text { Study group } \\
\mathrm{N}=48\end{array}$ & $\begin{array}{c}\text { Control group } \\
\qquad N=81\end{array}$ & $P$ value \\
\hline $\begin{array}{l}\text { Granular } \\
\text { Cytoplasm }\end{array}$ & 45 & 57 & 0.025 \\
\hline Dark Cytoplasm & 16 & 38 & \\
\hline Presence of vacuoles & 10 & 6 & 0.020 \\
\hline Presence of debris & 13 & 22 & \\
\hline Increased perivitelline space & 7 & 6 & \\
\hline Fragmented polar corpuscle & 13 & 20 & \\
\hline Change in oocyte shape & 0 & 2 & \\
\hline Changes on zona pellucida thickness & 45 & 79 & \\
\hline
\end{tabular}

The mean levels of FSH were $15.09 \pm 5.0 \mathrm{mUI} / \mathrm{ml} \mathrm{n}$ the study group, and $6.7 \pm 4.1 \mathrm{mUI} / \mathrm{ml}$ in the control group.

The morphological variables were analyzed and compared between the groups. The granular cytoplasm and presence of vacuoles variables in the study showed statistically significant differences from the control group, with $P$ values of $P=0.025$ and $P=0.02$, respectively (Table 1 ).

\section{DISCUSSION}

Human reproduction presents a number of challenges that need to be better understood. One of them refers to factors that can impact oocyte quality. Some conditions, such as PCOS are widely studied and its impact on oocyte quality is not fully understood. However, there are many conditions that still are poorly investigated as POI.

Premature Ovarian Insufficiency is a polygenic and multifactorial disease, which etiology can be attributed to several factors and is still being studied. According to Vilodre et al. .(2007), various causes can lead to POI or reduced number of follicles and/or defects in the follicular stimulation mechanism. However, there is no study about the events affecting oocytes previously to ovarian arrest.

Here we investigated patients with ovarian dysfunction presenting difficulties in oocyte retrieval, due to increased FSH levels, looking for oocyte morphological alterations. Eight variables of morphologic alterations were considered in the study and two of them showed statistically significant differences between cases and controls: granular cytoplasm and the presence of vacuoles, both more frequent in the study group.

One of the most fundamental determinants of oocyte developmental competence is nuclear maturity. This complex process involves: germinal vesicle breakdown, chromosome segregation, asymmetric meiotic division, expulsion of the first polar body and organization of oocyte cytoskeletal structure. The MII spindle, constructed of microtubules arranged around centrosome poles, plays an essential role in fertilization. Sperm penetration through the zona pellucida triggers resumption of meiosis and expulsion of the second polar body. Once the male and female pronuclear envelopes fuse, mixing maternal and paternal DNA, the chromosomes align along the newly formed mitotic spindle in preparation for segregation into separate blastomeres during embryonic cleavage (Wallbutton and Kasraie, 2010).

Cytoplasmic abnormalities that occur during oocyte maturation, especially those that interfere with meiotic spindle and intricate cytoskeletal structure, can adversely affect the ability of oocytes to undergo normal fertilization and embryo development.

Oocyte vacuolization is a common observation in clinical IVF. Ebner et al. (2005) found vacuoles in $3.9 \%$ of oocytes at collection, of which $66 \%$ had single, $21.3 \%$ had double and $12.7 \%$ had multiple vacuoles. De Sutter et al. (1996) and Alikani et al. (1995) suggest a slightly higher oocyte vacuolization rate $(5.7 \%$ and $12.4 \%$, respectively). Ebner et al. (2005) found no significant difference in clinical pregnancy rate but significantly higher miscarriage rates, lower birth weights and greater obstetric problems in pregnancies from cycles where some oocytes collected exhibited sERCs. Rienzi et al. (2008) identified significantly lower fertilization rates in vacuoled oocytes. Ebner et al., (2005) observed lower than normal fertilization rates in vacuoles up to $14 \mu \mathrm{m}$ ( $51.6 \%$ for single and $43.8 \%$ for multiple vacuoles) and suggest that fertilization cannot be expected in vacuoles $>14 \mu \mathrm{m}$.

Granularity is one of the abnormalities observed in the perivitelline space. These abnormalities are among the most important dimorphisms of the extracytoplasmic component. Hassan et al. (1998) found an association between the perivitelline space granularity and lower numbers of MII oocytes; however, perivitelline space granularity was not associated with fertilization rate, cleavage rate, and embryo quality. Interestingly, they found that granularity was positively associated with the dosage of human menopausal gonadotropins administered during stimulation. Our study suggests that FSH levels also have a negative impact on oocyte granularity.

In conclusion, higher FSH levels seem to impact negatively on oocyte morphology. Future studies with a larger population and investigating the association of these morphological abnormalities with clinical pregnancy rates would be interesting.

\section{CONCLUSIONS}

As a conclusion, patients with increased FSH levels presented oocytes with worst quality variables than controls. This can be indicative of ovarian aging and can affect negatively on the oocytes development into viable embryos.

\section{CONFLICT OF INTERESTS}

No conflict of interest have been declared.

\section{Corresponding author:}

\section{Monise Santos}

Instituto Ideia Fértil de Saúde Reprodutiva

Faculdade de Medicina do ABC

Santo André - SP

E-mail: monisesantos_@hotmail.com

\section{REFERENCES}

Alper MM, Garner PR, Seibel MM. Premature ovarian failure. Current concepts. J Reprod Med. 1986; 31: 699708. 
Anasti JN. Premature ovarian failure: an update. Fertil Steril. 1998; 70:115.

BenMeir A, Burstein E, BorregoAlvarez A, Chong J, Wong E, Yavorska T, Naranian T, Chi M, Wang Y, Bentov Y, Alexis J, Meriano J, Sung HK, Gasser DL, Moley KH, Hekimi S, Casper RF, Jurisicova A. Coenzyme Q10 restores oocyte mitochondrial function and fertility during reproductive aging. Aging Cell. 2015, 14:887-95.

Braat DDM. Diagnosis and diagnostic work up in suspected POI patients (Lecture) Primary Ovarian Insufficiency - POI: Update and Guideline presentation ESHRE POI Consesus (Utrecht, Netherlands) 2013.

Conway GS. Premature ovarian failure. Curr Opin Obstet Gynecol. 1997;9:2026.

De Sutter P, Dozortsev D, Qian C, Dhont M. Oocyte morphology does not correlate with fertilization rate and embryo quality after intracytoplasmic sperm injection. Hum Reprod. 1996;11:595-7.

Ebner T, Yaman C, Moser M, Sommergruber M, Feichtinger $\mathrm{O}$, Tews G. Prognostic value of first polar body morphology on fertilization rate and embryo quality in intracytoplasmic sperm injection. Hum Reprod. 2000,15:427-30.
Goswami D, Conway GS. Premature ovarian failure. Hum Reprod Update. 2005; 11:391 410.

HassanAli H, HishamSaleh A, ElGezeiry D, Baghdady I, Ismaeil I, Mandelbaum J. Perivitelline space granularity: a sign of human menopausal gonadotrophin overdose in intracytoplasmic sperm injection. Hum Reprod. 1998; 13:3425-30.

Mattison DR, Evans MI, Schwimmer WB, White BJ, Jensen $B$, Schulman JD. Familial premature ovarian failure. Am J Hum Genet. 1984; 36:13418.

Moussa M, Shu J, Zhang XH, Zeng F. Maternal control of oocyte quality in cattle "a review". Anim Reprod Sci. 2015; 155:1127.

Rienzi L, Ubaldi F, Iacobelli M, Romano S, Minasi G, Ferrero S, Sapienza F, Baroni E, Greco E. Significance of morphological attributes of the early embryo. Reprod Biomed Online. 2005; 10:669-81.

Veeck LL, ed. Atlas of human oocyte and early conception. Baltimore: Williams \& Wilkins; 1986.

Vilodre LC, Moretto M, Kohek MB, Spritzer PM. [Premature ovarian failure: present aspects]. Arq Bras Endocrinol Metabol. 2007,51:9209. 